
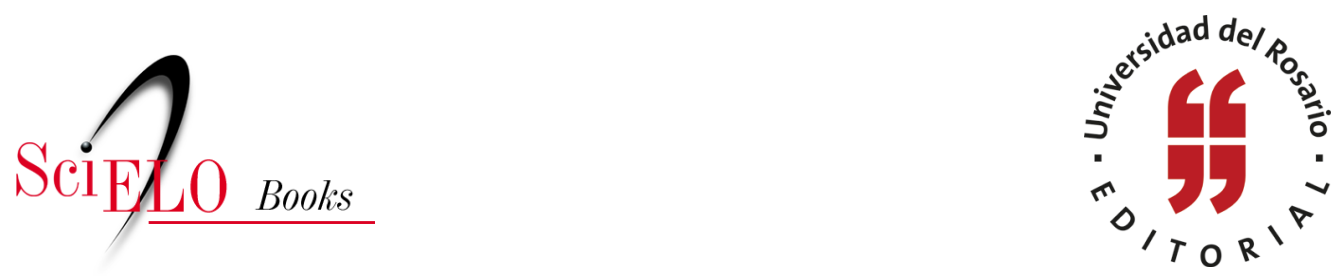

\title{
"La serena simplicidad de nuestro espíritu" imagen de progreso e identidad nacional a partir de la participación de Chile en la Exposición Iberoamericana de Sevilla de 1929
}

\author{
Sylvia Dümmer Scheel
}

\section{SciELO Books / SciELO Livros / SciELO Libros}

DÜMMER SCHEEL, S. "La serena simplicidad de nuestro espíritu”: imagen de progreso e identidad nacional a partir de la participación de Chile en la Exposición Iberoamericana de Sevilla de 1929. In: SCHUSTER, S., ed. La nación expuesta. Cultura visual y procesos de formación de la nación en América Latina [online]. Bogotá: Editorial Universidad del Rosario, 2014, pp. 69-81. Textos de ciencias humanas collection. ISBN: 978-958-738-524-3. https://doi.org/10.7476/9789587385243.0005.

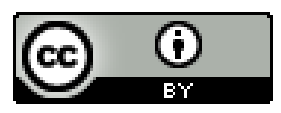

All the contents of this work, except where otherwise noted, is licensed under a Creative Commons Attribution 4.0 International license.

Todo o conteúdo deste trabalho, exceto quando houver ressalva, é publicado sob a licença Creative Commons Atribição 4.0.

Todo el contenido de esta obra, excepto donde se indique lo contrario, está bajo licencia de la licencia Creative Commons Reconocimento 4.0. 


\title{
"La serena simplicidad de nuestro espíritu": imagen de progreso e identidad nacional a partir de la participación de Chile en la Exposición Iberoamericana de Sevilla de 1929
}

\author{
Sylvia Dümmer Scheel \\ Freie Universität Berlin
}

Cuando el gobierno chileno aceptó la invitación de participar en la Exposición Iberoamericana de Sevilla, en 1929, lo hizo con el objetivo de atraer inversión, inmigrantes y turistas, al tiempo de incrementar "el prestigio nacional". La imagen de nación que se quería dar para ello era la de ser un país de progreso que destacaba sobre sus pares latinoamericanos. Como sostenía el diario El Mercurio, era necesario "que las naciones más adelantadas [...] sepan que Chile en la actualidad, se encuentra en muchos de los aspectos de progreso mundial a la altura de las naciones más civilizadas" (1927a). Este era el mismo discurso que había planteado el país en su asistencia a las grandes exposiciones de fines del siglo XIX y principios del XX, donde para parecer civilizado había recurrido a pabellones de arquitectura francesa que lo identificaran con Europa (Hernández 2006; Norambuena 2002-2003). En 1929 , sin embargo, ya no era posible recurrir a dicha estrategia. Un nuevo nacionalismo de corte culturalista y la consiguiente transformación de los imaginarios nacionales hicieron que en esta ocasión surgiera con especial fuerza un interés nuevo: poner en escena una identidad clara y diferenciadora que fuera verdadera representación de "lo chileno". Organizadores, representantes de diversos gremios y la prensa escrita exigían que en el pabellón de Chile en Sevilla se hiciera sentir "el alma nacional" (El Mercurio 1927b). Ello significó un verdadero desafío para 
los organizadores, no solamente porque se vieron obligados a desarrollar símbolos hasta ahora inéditos para representar al país, sino porque las interpretaciones sobre lo "genuinamente nacional" no siempre iban en la misma línea que las ideas de progreso. Cómo se intentó hacer compatibles ambas en la escenificación del país, es el tema que abordo en este ensayo.

\section{El "alma de Chile"}

La transformación en la definición de "lo chileno" se había ido conformando desde el cambio de siglo, cuando una concepción más republicana y cívica de nación - como se puede ver en la figura 1, que muestra gráficas publicitarias de fines del siglo XIX que relacionan la palabra Chile o nación con símbolos republicanos de corte francés - fue dando paso a otra de corte más bien etnolingüístico. Dicha transformación en la concepción de lo nacional se había dado bajo la influencia de corrientes ideológicas provenientes de Europa. Los conceptos planteados por el romanticismo alemán, donde se promovía la existencia de un "genio nacional" con existencia propia (Volksgeist), sumado a las ideas del social darwinismo francés, que ponía el relieve en la base racial de las comunidades, fueron dando forma a una nueva idea de nación que desplazaba la definición republicana por una de corte étnico y lingüístico. El idioma, las tradiciones, los recuerdos compartidos, el folclor y la "raza" se convertían en elementos relevantes a la hora de definir los lazos nacionales. ${ }^{1}$ Dentro de ese marco ideológico, en Chile comenzó hacia el cambio de siglo una exploración identitaria basada en lo cultural, que escarbaba en el pasado en busca de tradiciones y representantes raciales originarios, y que fue tomando forma a través de la obra de pintores, escritores, músicos, arqueólogos y antropólogos. Los personajes populares de campo y ciudad, junto con los miembros de etnias indígenas rescatados por los artistas mesocráticos, se convirtieron en verdaderos "tipos chilenos" que simbolizaban desde su representación tipificada los nuevos valores de lo nacional (Subercaseaux 2007, 137). A fines de la década de los veinte ya se habían posicionado en la representación oficial, como se puede ver en las portadas de la revista Chile con que el gobierno de Carlos Ibáñez del Campo promovía al país en el exterior (figura 2).

1 Para más información sobre el tema véase Mosse (1997). 


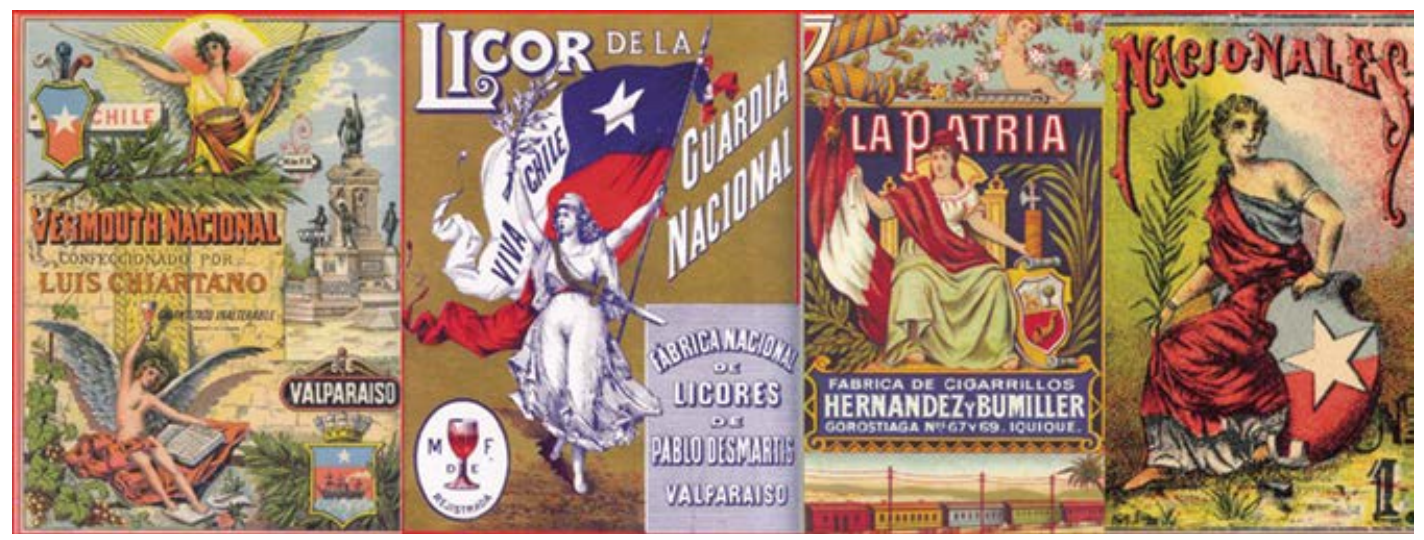

Figura 1. Marcas chilenas que aludían a la patria mediante símbolos de la iconografía republicana francesa a fines del siglo XIX

Fuente: Álvarez (2008).
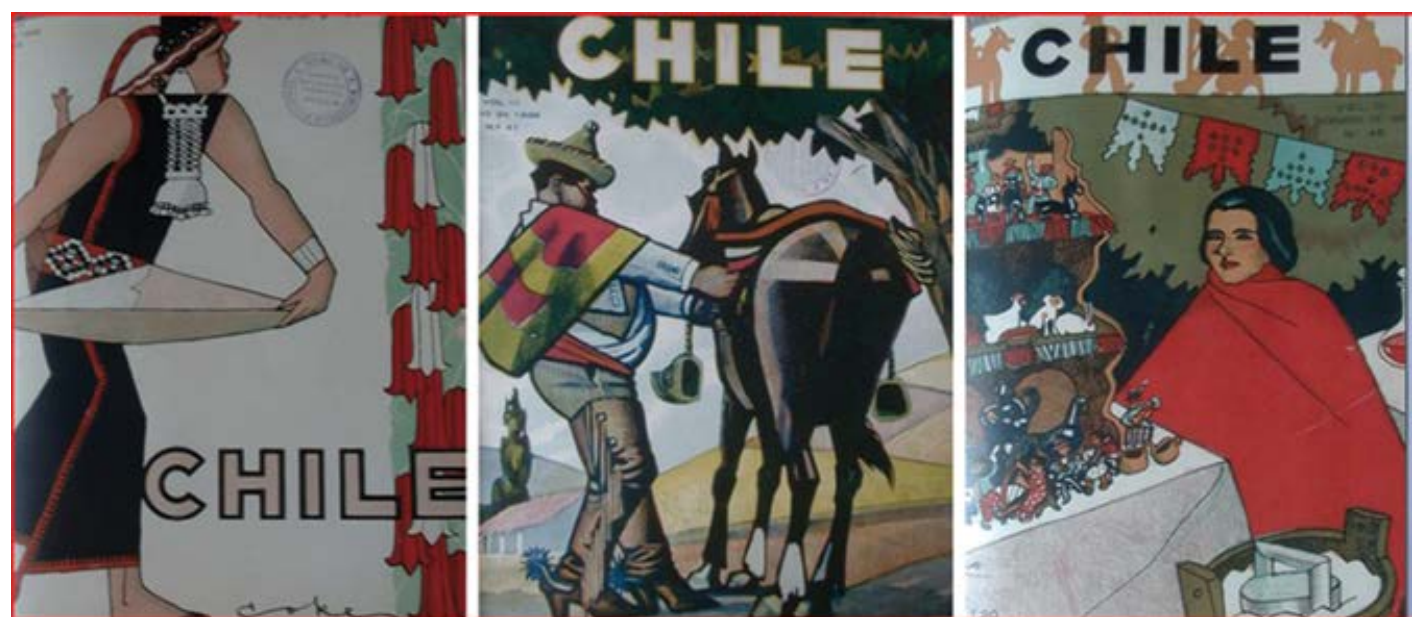

Figura 2. Portadas de la revista Chile, en 1928, con motivos indígenas y populares Fuente: revista Chile 40 (junio de 1928), 40 (julio de 1928) y 46 (diciembre de 1928).

La participación de Chile en la Exposición Iberoamericana de Sevilla hizo eco de las transformaciones ocurridas en los imaginarios nacionales, y así fue como por primera vez en la historia de la participación chilena en este tipo de eventos se abandonó la estética arquitectónica europea y se organizó una exhibición que incluía aspectos folclóricos e indigenistas. De este modo, la decoración del interior del edificio contó con varios detalles inspirados en el arte indígena, como el 
mobiliario de estilo araucano, ${ }^{2}$ diseñado por Alfredo Cruz Pedregal. El recorrido del visitante era acompañado por canciones propias del folclor nacional que sonaban desde un gramófono, mientras que en el anfiteatro del edificio se exhibían obras de teatro costumbristas y eventos de danza o música folclórica (El Mercurio 1927c). El gobierno pidió además a los artistas Arturo Gordon y Laureano Guevara que confeccionaran los murales del interior del edificio utilizando "motivos nacionales”, lo que resultó, especialmente la pintura de Guevara, un verdadero glosario de símbolos criollos. La Comisión Organizadora financió, por su parte, la publicación de obras de antropología y cultura popular que fueron exhibidas en la biblioteca del pabellón.

Sin embargo, lo más novedoso fue la habilitación de dos salas del edificio para la Sección de Arte Araucano y Popular. Hasta entonces, en los pabellones de Chile en el exterior había bastado con salones de bellas artes para dar la nota cultural. Ahora, la Subcomisión de Bellas Artes del Comité Organizador preparó, además de las tradicionales muestras de cuadros y esculturas, la exhibición de muestrarios de objetos típicos del arte campesino y de la industria mapuche, objetos que fueron recolectados a lo largo del país por la artista y miembro de la subcomisión Elena Montero de Leiva. Así, en la Sala de Arte Araucano se exhibieron telares, alfombras, ponchos, alfarería, instrumentos musicales, platería y armas de origen mapuche; mientras que en la Sala de Arte Popular se dispusieron canastitos de Panimávida, tejidos de lana de fabricación doméstica, gredas de Quinchamalí, tejidos en crin y raíces y juguetes de trapo fabricados por campesinos, aperos de montar, monturas y espuelas. Además se montaron, en dioramas iluminados, escenificaciones de las costumbres y tradiciones tanto de araucanos como de campesinos y se exhibió la reproducción de una ruca araucana con todos sus atributos (figura 3 ). ${ }^{3}$

2 Los indígenas del centro y sur del país se llaman a sí mismos mapuche (hombre de la tierra). El término araucano les fue dado por los conquistadores españoles. En este artículo se utiliza este término, por tratarse del vocablo que aparece utilizado en las fuentes consultadas y porque hace hincapié, precisamente, en la connotación de alteridad con que eran percibidos por las élites a cargo de la escenificación de lo nacional.

3 Cabe notar que la representación indígena en el pabellón se limitó casi exclusivamente a la etnia araucana, aun cuando otorgó también cierto espacio a los indios fueguinos, como ocurrió en el mural de Laureano Guevara. De hecho, aunque curiosamente ninguna otra fuente lo menciona, según el Catálogo-guia del Pabellón de Chile se habría montado una sección sobre los indígenas de Tierra del Fuego, en el tercer piso del pabellón. Con todo, salvo estos y la cultura rapanui de isla de Pascua, aludida en la fuente monumental del escultor Ortiz de Zárate, las demás culturas precolombinas del país no estuvieron presentes en el montaje. Ello, probablemente, porque pese a estar siendo estudiadas 


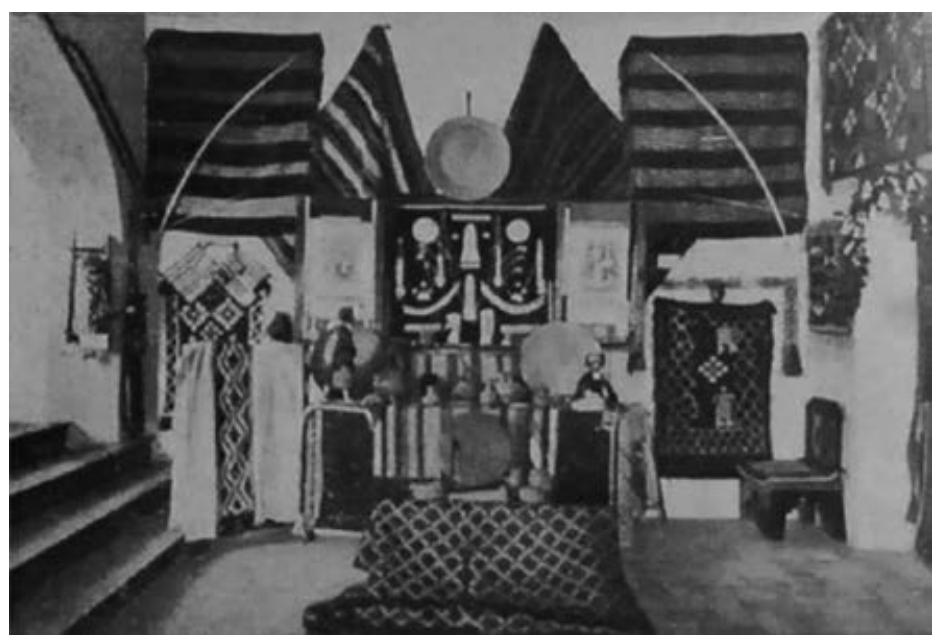

Figura 3. Sala de Arte Araucano

Fuente: Catálogo-guía del Pabellón de Chile (1929-1930).

De las palabras de los organizadores se desprende que la artesanía campesina y araucana no se exhibía en el Pabellón de Chile, porque se le considerara de gran valor artístico —ese rol ya lo cumplían las obras de la Sala de Bellas Artes—, sino por tratarse de las expresiones de la base étnica y racial de la nación, porque en ellas se manifestaba realmente la "raza", y no en los artistas de la academia. De hecho, según Alberto Cabero, en Chile y los chilenos, el espíritu del “alma colectiva” (1940, 144) estaba presente, más que en las almas excepcionales, en el tipo generalizado que definía la raza, perteneciente a las clases populares. Por lo demás, había en el arte popular una cierta inocencia y una falta de pretensiones que lo hacían parecer más puro, como expresaba el colaborador de El Mercurio, Guillermo Muñoz Medina (1927): "Ese arte nacido sin obsesiones técnicas ni preocupaciones estilísticas es el que mejor recoge y reproduce la vida emocional de una nación”. El rol de las salas de Arte Araucano y Popular no era destacar en términos artísticos, sino dar expresión al "alma nacional”. Sus creaciones le otorgaban a Chile el pasado remoto y el sello ancestral que se necesitaba bajo el prisma del nacionalismo etnolingüístico para definirse como país.

por los arqueólogos y antropólogos de la época, no formaban todavía parte del repertorio visual de los imaginarios nacionales. 
Pese a ello, las posiciones frente a la conveniencia de exhibir contenidos indígenas estaban divididas. De hecho, la iniciativa de montar la Sección de Arte Araucano y Popular desató una gran polémica. La prensa acusó de una verdadera campaña llevada a cabo por algunas personas para que Elena Montero desistiera de la idea de organizar la exhibición, la cual se llevó a cabo únicamente gracias a que el mismo presidente de la República intervino a su favor (Chile 1929a, 33; El Mercurio 1930). Sin embargo, ello no significó que el discurso se unificara. Los organizadores estaban divididos entre quienes querían publicitar la cultura indígena y popular como definición de lo nacional y quienes preferían omitirla en pro de un discurso más "blanco".

Para varios de los organizadores, la exhibición de una muestra indígena chocaba con el discurso de progreso que tanto al gobierno de Ibáñez como a las élites les interesaba posicionar para lograr los objetivos económicos del país. Por lo demás, la idealización que del indígena tenían artistas y literatos no era compartida por muchos intelectuales y políticos que veían en el araucano solo atraso e inferioridad ${ }^{4}$ y que, adscribiéndose a una corriente más hispanista, preferían enfatizar la rama española de la "raza chilena”. Incluso el embajador de Chile en España recomendaba insistir en Sevilla que Chile consistía en "un pueblo íntegramente blanco".

Las posturas enfrentadas no lograron aunarse, y en vez de optarse por una u otra, se les dejó coexistir, lo que generó una narración final llena de contradicciones. Así, mientras la Sala de Arte Araucano y Popular se convertía en uno de los puntos más interesantes del pabellón, obtenía una Medalla Gran Premio por parte de las autoridades españolas (Catálogo-guía 1929-1930) y era reconocida por el gobierno de Ibáñez con la decisión de exhibir la muestra en París el año entrante (El Mercurio 1930), en el Catálogo-guia del Pabellón de Chile (1929-1930) se afir-

4 Aunque hubo estudiosos que intentaban analizar al indígena chileno de manera científica y artistas que rescataban su estética, la mayoría de los intelectuales nacionalistas de la época eran sumamente críticos hacia su cultura. Alberto Cabero, autor de Chile y los chilenos, describía al indígena araucano como un pueblo inferior, con limitadas posibilidades mentales y una incapacidad para evolucionar, además de ser supersticioso y ladrón. El antropólogo Tomás Guevara también diagnosticaba una inferioridad de sus capacidades intelectuales, mientras el escritor Joaquín Edwards Bello se quejaba de que los "supuestamente superiores araucanos ni siquiera habían dejado la edad de piedra en el año 1500”, adjudicándoles todos los vicios imaginables: fatalismo, flojera, alcoholismo. También la poeta Gabriela Mistral culpaba al araucano por la pereza biológica de la raza, y hubo quienes desautorizaron las mitificadas imágenes indígenas propuestas por Ercilla en La araucana y por Pedro de Oña en Arauco domado por considerarlas exaltaciones imaginarias e imposibles, totalmente alejadas de la realidad. 
maba que "la masa de la población actual es casi toda descendiente de los colonos españoles y otras naciones europeas, siendo muy pequeña la mezcla con los indios araucanos". Mientras la decoración de inspiración indígena buscaba otorgarle un pasado ancestral al país, en la Sala de Historia del pabellón la narración comenzaba con la conquista española y omitía cualquier acontecimiento anterior, y en el libro oficial Chile en Sevilla se mencionaba incluso que los conquistadores españoles habían hecho su llegada a "tierras vírgenes" (Jara y Muirhead 1929). Y aunque el arte araucano y popular se exhibiera como una "expresión de la raza”, en el Catálogo-guía se explicaba que el núcleo de la raza chilena estaba conformado por los conquistadores españoles y sus familias. 5

Por cierto, pese a estas diferencias de opinión había un punto de partida compartido en relación con el mundo indígena: ninguno de los organizadores quería que el país entero fuera identificado como tal. Desde el punto de vista de los defensores de montar la Sala de Arte Araucano, el éxito del montaje consistiría en exhibir una muestra de rasgos propios sin que ello se prestara a generalizaciones hacia el resto del país. Porque una cosa era mostrar las expresiones de los pueblos originarios, y otra, muy distinta, "que nos creyeran indígenas a todos" (ElMercurio 1930). No por nada el mismo presidente Ibáñez, quien promovía la exhibición de las artes del pueblo, manifestaba no obstante que fueran presentadas "en proporcionada latitud” (El Mercurio 1930). Vale decir, sin exagerar. Y no solo no se exageró en cuanto a cobertura, sino que además se aisló simbólicamente a estos grupos del resto del país. El hecho de reunir todos los objetos de su creación, independiente de su naturaleza, en una sala aparte, remarcaba la condición de alteridad que representaban sus autores para las élites a cargo de representar al país. Lo araucano y lo popular estaría presente como expresión del “espíritu nacional”, pero sin dejar que se desbordara ni pusiera en duda el adelanto y progreso del país.

\section{Un país frío}

Para demostrar que Chile era un país civilizado, además de insistir en la blancura de la población, se creyó necesario recalcar que se diferenciaba enormemente de sus pares latinoamericanos. Pese a que un sentimiento de excepcionalidad frente al resto del continente se incubaba entre los chilenos desde las primeras décadas

5 Ciertamente, el discurso de nación era emblanquecido con mayor fuerza en aquellos soportes que iban dirigidos a un público más seleccionado: las publicaciones Chile en Sevilla y el Catálogo-guía fueron distribuidos por los cónsules de Chile a posibles inversionistas en sus respectivos países. 
de vida republicana, y surgió el mito de ser "los ingleses de América Latina”, había conciencia también de que dichos matices no eran percibidos por Europa, para quienes, como había advertido el embajador en España Emilio Rodríguez Mendoza, se creía que la América toda era "una enorme selva inflamada" (1927, 2). Era necesario tomar distancia de los prejuicios y los estereotipos de atraso y desorden desde los que era percibida América Latina, y reforzar una identificación con Europa que, de hecho, muchos chilenos sentían cierta. Surgía así la pregunta de cómo mostrarse europeos y desarrollados a través del Pabellón sin pasar a llevar lo que se entendía como "espíritu nacional". Recurrir al arte indígena como inspiración arquitectónica no era una opción viable, no solamente por los desencuentros que generaba y porque contradecía los aires de progreso que se le quería dar a la muestra, sino también porque se tenía conciencia de la inferioridad del arte araucano con respecto al arte maya, azteca e inca, con los cuales sería comparado.

La propuesta arquitectónica del arquitecto Juan Martínez Gutiérrez, que fue la elegida por el jurado de la comisión organizadora, pareció ofrecer una solución vanguardista y original a este requerimiento. Su edificio, en vez de inspirarse en estilos arquitectónicos de corte hispanista o indigenista, como hicieron los demás pabellones latinoamericanos, resultó ser una representación simbólica que evocaba la cordillera de los Andes a través de macizos volúmenes ascendentes coronados por una torre, pintado de blanco con toques grises y rojizos (figura 4). Según las palabras del arquitecto, el pabellón interpretaría el espíritu chileno "sin recurrir para ello a motivos coloniales, sino a agrupaciones de volúmenes y trozos de escultura y pintura capaces de sugerir el ambiente de un pueblo y de hacernos adivinar su cultura" (El Liberal, 1928). De hecho, la geografía del país era un elemento que, junto a los tipos chilenos y el arte indígena, había cobrado gran relevancia en la definición de lo nacional en las últimas décadas, por estar presente en la literatura y arte costumbrista. Por todas estas evocaciones, el Pabellón de Chile fue la primera obra concebida "inspirándose en lo nuestro, en lo típico, en nuestros ambientes" (ElMercurio 1927d) y que expresaba "los rasgos característicos de la idiosincrasia nacional" (Chile 1929b).

Sin embargo, la cordillera tenía una connotación simbólica que iba mucho más allá del hecho de ofrecer un "rasgo propio" para representar al país. Según las ideas que circulaban en la época, era también una demostración del grado de civilidad de los chilenos. 


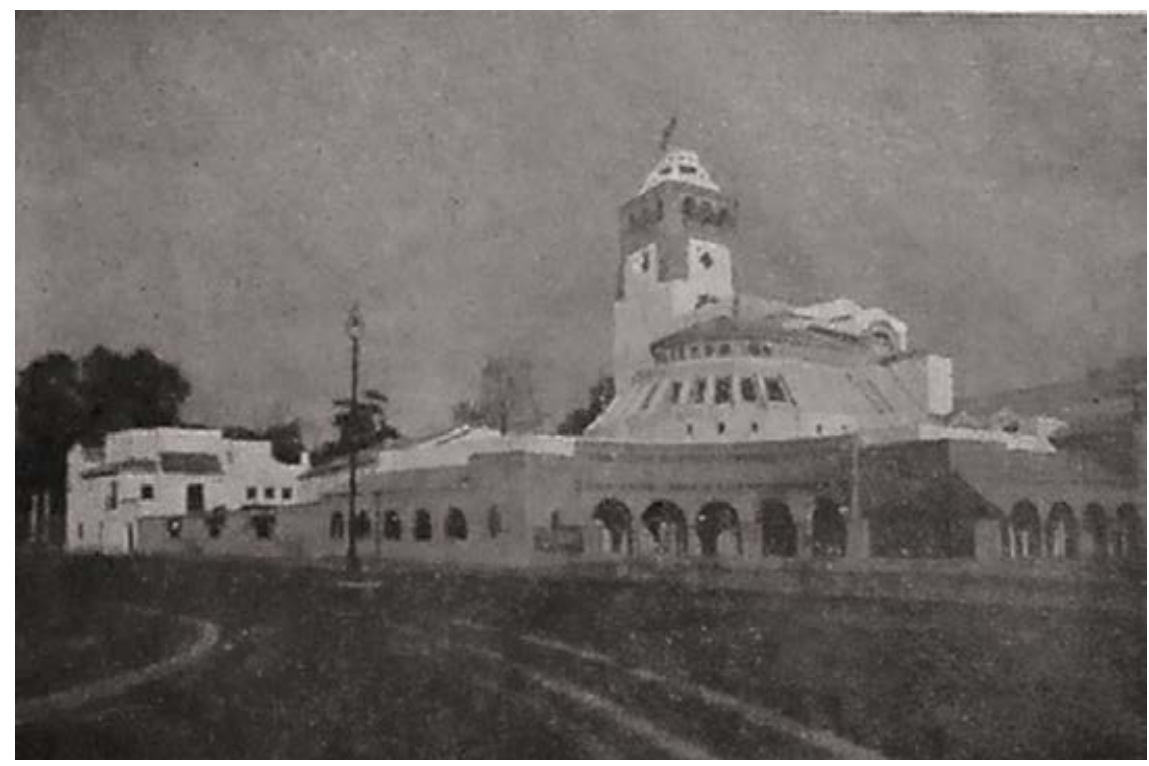

Figura 4. Pabellón de Chile en la Exposición Iberoamericana de Sevilla, 1929

Fuente: Catálogo-guia (1929-1930).

Para comprender cómo se llegaba a esta asociación, hay que tener presente que en el contexto mental de la época se creía en la existencia de razas con rasgos sicológicos intrínsecos, los cuales habían sido influenciados de manera determinista por el medio físico (especialmente el clima) en que se desarrollaba la población. De hecho, desde el siglo XviII circulaban en Europa ensayos que vinculaban determinados rasgos sicológicos a un clima particular, siendo la tesis dominante la que asociaba el clima templado al desarrollo, y el calor, a la barbarie. Tales ideas afectaron, sin duda, la imagen del continente americano. Los estigmas de inferioridad que lo habían marcado desde el descubrimiento adquirieron entonces una sólida base argumental. Buffon y De Pauw impusieron la visión de América como una tierra débil e inmadura, cuyo clima determinaba la inferioridad de sus habitantes. ${ }^{6}$ No tardó en expandirse la idea de la holgazanería e ineptitud de sus gentes, y del trópico como lugar de excesos y barbarie. A principios del siglo XIX, el estudioso

6 Buffon estableció que las especies animales del continente americano eran más débiles y pequeñas - $\mathrm{y}$, por lo tanto, inferiores - que las europeas, inferioridad que se explicaría, en una visión determinista, por la inmadurez del medio físico. De Pauw incluyó luego al hombre en la tesis buffoniana y extendió, así, la idea de la inferioridad al habitante americano. En Gerbi (1982). 
alemán Alexander von Humboldt también concluyó, ahora desde un "método científico" pero aceptando las tesis deterministas de la época, que "la civilización de los pueblos está casi constantemente en proporción inversa a la fertilidad de los suelos que la habitan". El clima, la fuerza de la vegetación y la presión ambiental del trópico derivaban, por consiguiente, en salvajismo (Brading 1991, 553-565). Así, el progreso social solamente podía darse en climas templados como el europeo y el trópico quedaba irreversiblemente asociado a incivilidad.

Cuando el social darwinismo llegó con mayor fuerza a Chile, a principios del siglo XX, no faltaron estudiosos en el país que recogieran estas doctrinas. Entre ellos, el escritor y ensayista Alberto Cabero $(1940,171)$ creyó firmemente en la influencia del clima en la población y sostuvo la inferioridad del trópico, argumentándola biológicamente. Sin embargo, según explicaba en su libro Chile y los chilenos, no había ocurrido lo mismo en dicho país, cuyo clima era templado y, por tanto, "favorable al desarrollo y progreso de las razas que la habitan” (39 y 40). La pobreza del suelo obligaba a trabajar arduamente para subsistir, formando una población esforzada. El clima de Chile, además, "incita a la actividad y predispone a someter el sentimiento a la razón” (41). El antropólogo Tomás Guevara defendía la misma idea cuando explicaba que "en los países templados, la fertibilidad [sic] del suelo es menos que en las regiones cálidas, i para intensificarla se requiere un trabajo humano constante, particularmente en las topografías quebradas, que viene a vigorizar al fin el organismo de los individuos" (1925, 349). Gracias a su clima, entonces, el país se alejaba del "desborde imaginativo" tropical.

Desde el determinismo geográfico de la época, entonces, el argumento principal esgrimido por los organizadores de la concurrencia de Chile a Sevilla fue que el país se encontraba muy lejos del trópico y que se trataba, antes bien, de un país frío de geografía escarpada. Ello habría permitido el desarrollo de una población racional, esforzada y, especialmente, de espíritu trabajador. La imagen de un país frío permitía acercar simbólicamente Chile a Europa y alejarlo del continente latinoamericano, mientras la idea asociada de una raza laboriosa y esforzada daba tranquilidad a inversionistas e inmigrantes.

Para graficar este argumento, el embajador en España Emilio Rodríguez Mendoza proporcionó sugerentes metáforas, explicando que en Chile:

[...] la Araucaria, de clima frío, que crece y vive entre la lluvia y nieve, reemplaza bizarramente a las palmeras, símbolo decorativo de la zona inflamada del continente [...] Parece indicado, pues, la conveniencia y el derecho de mostrar en 
la próxima exposición que nuestro clima es templado, que en lugar del plátano, se da la manzana. $(1927,2)$

Se trataba, a final de cuentas, de dejar muy claro que Chile no era un país tropical ni bananero. Aunque se llevaron a Sevilla un par de araucarias como sugería el embajador, el símbolo principal para representar estas ideas fue la cordillera nevada. Esta estuvo presente no solamente en la arquitectura del pabellón, sino también en los murales de Laureano Guevara y Arturo Gordon y, especialmente, en la portada del libro oficial publicado para el certamen, Chile en Sevilla, donde los colores azules del diseño reforzaban la idea de frío (figura 5).

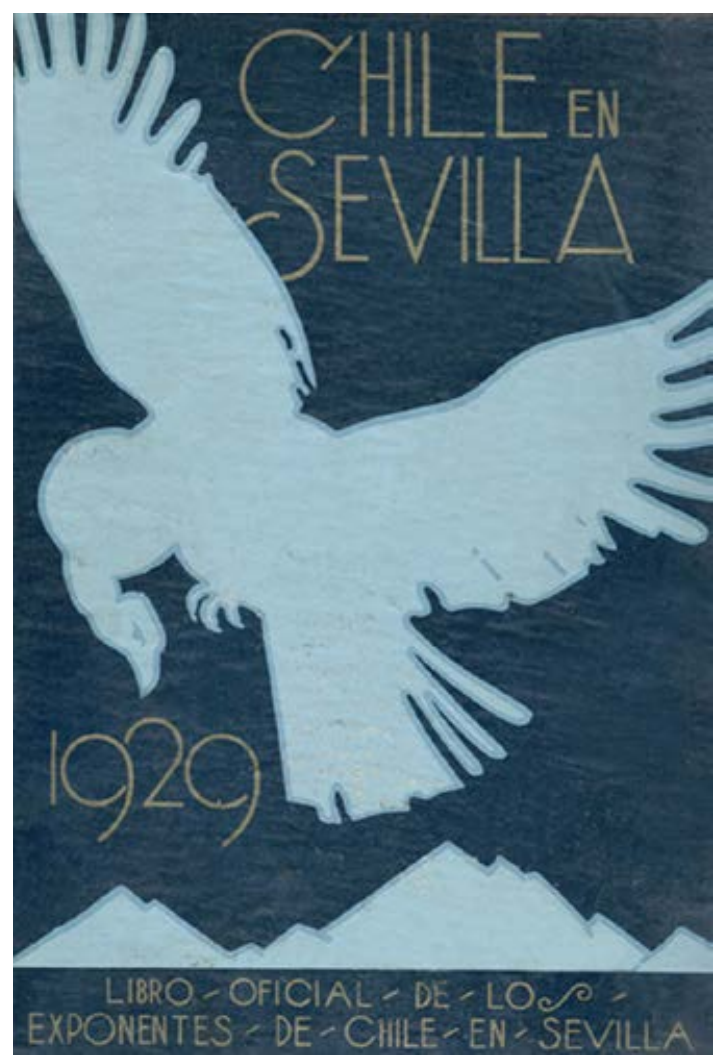

Figura 5. Portada del libro oficial Chile en Sevilla

Fuente: Jara y Muirhead (1929).

Reforzando estos argumentos, el espíritu racional y esforzado de la población se intentó comunicar también a través de otro rasgo que se consideraba intrínseco a 
ella y que estaba presente en la autoidentificación del chileno desde hacía décadas, el cual era la sobriedad, impuesta del mismo modo por el medio físico. Por ello, en la revista de la Cancillería se pedía acudir a Sevilla de forma "austera y ordenada", para dar así la idea de "un país sobrio, trabajador, rico y progresista” (Chile 1929c, 3). Otras voces, entre tanto, pidieron que Chile se presentara en Sevilla "sin tropicalimos ni exageraciones”. Se procuró diseñar con austeridad desde los folletos estadísticos hasta la disposición de los objetos en el interior del edificio. El Pabellón de Juan Martínez, por su parte, cumplió con estas expectativas y fue celebrado por la mayoría de los arquitectos precisamente por sus rasgos de sobriedad y severidad, que lograban expresar, según juicio de El Mercurio, "la serena simplicidad de nuestro espíritu” (1927e). Además de la simpleza de las formas a gran escala, destacaba la escasez relativa de detalles decorativos en el edificio, que contrastaban con los edificios rebosantes de tallados, mosaicos y dibujos indigenistas de México, Perú, Colombia o Guatemala. En comparación con ellos, el edificio de Chile, con grandes muros desnudos y las bóvedas interiores vacías, parecía más bien un claustro de austeridad monacal.

\section{Conclusiones}

Aunque la Exposición Iberoamericana de Sevilla fue la instancia más indigenista en la representación de Chile en el exterior — en la Feria Mundial de Nueva York de 1939 ya se le bajaría el perfil a lo araucano-, el indígena como representación de lo nacional nunca logró consenso en la sociedad chilena y estuvo siempre limitado a ofrecer simplemente un par de rasgos estéticos que decoraran la expresión de lo nacional.

De este modo, la cordillera resultó ser un símbolo mucho más funcional que el folclor o el arte indígena para representar al país en el exterior y cumplir con los objetivos económicos que se perseguían con la asistencia a la exposición. Con su representación, se evitaban el riesgo de comunicar atraso y barbarie que habría conllevado una estética indigenista, y se optaba por un símbolo de mayor consenso nacional. Sus múltiples connotaciones simbólicas permitieron sugerir el grado de civilización de la nación y esbozar similitudes climáticas, geográficas e incluso raciales con Europa, dando expresión, al mismo tiempo, al "alma nacional" del país. Dicha metáfora de país frío tendría, de hecho, larga duración. Cuando Chile, en 1992, volvió a acudir a una exposición internacional en Sevilla, el elemento elegido como representación de lo nacional fue un enorme iceberg de hielo antártico que lució dentro de su pabellón. 


\section{Bibliografía}

Álvarez, Pedro. 2008. Marca registrada. Santiago: Ocho Libros.

Brading, David A. 1991. Orbe indiano: de la monarquía católica a la república criolla (1492-1867). México: FCE.

Cabero, Alberto. 1940 [1926]. Chile y los chilenos. Santiago: Imp. Cervantes.

Catálogo-guia del Pabellón de Chile (1929-1930). Sevilla: Tip. A. Padura.

Chile. 1929a. "El alma de Chile en Sevilla", octubre, 33.

Chile. 1929b. n. ${ }^{\circ}$ 51, mayo.

Chile. 1929c. "Editorial: Chile en Sevilla", n. ${ }^{\circ}$ 56, octubre: 3.

El Liberal. 1 de noviembre de 1928.

El Mercurio. 1927a. "Exhibamos ampliamente el progreso nacional", 10 de agosto.

El Mercurio. 1927b. 19 de agosto.

El Mercurio. 1927c. "El teatro chileno a la Exposición de Sevilla”, 21 de julio.

El Mercurio. 1927d. "Conozcamos la casa de Chile en Sevilla”, 23 de octubre.

El Mercurio. 1927e. 29 de diciembre.

El Mercurio. 1930. "Éxito de la Exposición de Arte Chileno en París”, 1 de abril.

Gerbi, Antonello. 1982. La disputa del nuevo mundo. México: FCE.

Guevara, Tomás. 1925. Historia de Chile: Chile prehispano. Santiago: Balcells \& Co.

Hernández, Carmen. 2006. "Chile a fines del siglo XIX: exposiciones, museos y la construcción del arte nacional”. En Galerias del progreso: museos, exposiciones y cultura visual en América Latina, editado por Jens Andermann y Beatriz González-Stephan, 261-290. Rosario: Viterbo.

Jara, Aníbal y Manuel Muirhead. 1929. Chile en Sevilla: el progreso material, cultural e institucional de Chile en 1929. Santiago: Cronos.

Mosse, Georg L. 1997. La cultura europea del siglo XIX. Barcelona: Ariel.

Muñoz Medina, Guillermo. 1927. "Nuestra música en Sevilla”. El Mercurio, 7 de agosto.

Norambuena, Carmen. 2002-2003. "Imagen de América Latina en la Exposición Universal de París de 1889”. Dimensión Histórica de Chile 17-18: 87-121.

Rodríguez Mendoza, Emilio. 1927. Carta de Emilio Rodríguez Mendoza, embajador de Chile en España, a Conrado Ríos Gallardo, ministro de Relaciones Exteriores de Chile, Madrid, España, 5 de septiembre de 1927. En Archivo Ministerio de Relaciones Exteriores, Chile, vol.1103, n. ${ }^{\circ}$ 140: 2.

Subercaseaux, Bernardo. 2007. Historia de las ideas y de la cultura en Chile: nacionalismo y cultura. Vol. 4. Santiago: Editorial Universitaria. 